\title{
ACERCA DE los aspectos generales de la HERMENÉUTICA CONSTITUCIONAL
}

\section{Rodrigo PicA*}

RESUMEN: El presente trabajo explora el concepto de interpretación constitucional, su contenido, reglas y fronteras, formulada, desde una perspectiva crítica, a partir del constitucionalismo contemporáneo como fenómeno bistórico y del pensamiento hermenéutico posmoderno, buscando la confluencia y los puntos de contacto entre ambos.

Palabras Clave: Interpretación constitucional - Hermenéutica - Jurisdicción constitucional.

\section{ACERCA DE LOS ASPECTOS GENERALES DE LA HERMENÉUTICA CONSTITUCIONAL}

ABSTRACT: This work explores the concept of constitutional interpretation, its contents, rules and frontiers, formulated from a critical view of contemporary constitutionalism as a historical phenomenon and as the post-modern bermeneutic thought, searching the junction among both.

KEY wORDS: Constitutional Interpretation - Hermeneutics - Constitutional Jurisdiction.

SUMARIO: I. Contexto preliminar. II. Conceptos fundamentales para una Teoría General Hermenéutica y su relación con la Constitución. III. Una metodología de la interpretación constitucional: tarea pendiente. IV. Corolario.

\section{Contexto PReliminaR}

Existe consenso generalizado en que la interpretación de la Constitución es el núcleo del Derecho constitucional actual, al punto que el tan antiguo aforismo norteamericano "la Constitución es la Constitución después de interpretada" ha pasado a universalizarse y ser una

Abogado. Profesor de la Facultad de Derecho Universidad Central de Chile. Correo electrónico: rodrigopica@tie.cl

Artículo recibido el 21 de septiembre de 2005. Aprobado el 16 de diciembre de 2005. 
premisa fundamental del nuevo Derecho público, incluso en la, hasta hace poco, tan legalista y formalista Europa continental. Así, hoy, el Derecho constitucional alemán se construye en gran parte en torno a la jurisprudencia del Tribunal constitucional de Karlsruhe, y el sistema de jurisdicción constitucional italiano es estudiado en casi todo el mundo occidental como una de las obras de derecho más perfectas de la posguerra; qué hablar del caso norteamericano, donde la judicial review, la Constitutional adjudication y la constitutional interpretation tienen más de 200 años, y donde el Derecho constitucional se estudia mayormente en torno a un casebook, un libro que sistematiza el ramo en torno a la interpretación constitucional de los tribunales en torno a los casos más relevantes a lo largo de la historia.

El constitucionalismo en Europa cambió hace ya más de 50 años, baste leer en nuestros días a autores como Konrad Hesse, Capeletti, Favoreau, Troper, y otros más conocidos por nosotros como lo son los autores españoles: Rubio Llorente, los ya clásicos García de Enterría y García Pelayo entre otros tantos, pero todos con un cimiento común: el reconocer a la Constitución el carácter de norma jurídica, y aunque suene redundante, de norma justiciable. Todo el resto no es otra cosa que las consecuencias que de ello se derivan: tribunales que la apliquen, acciones que ejercer, procedimientos, jueces constitucionales, y obviamente, interpretación de la norma constitucional. Así por ejemplo, la doctrina española enseña que "la teoría de la interpretación es hoy el núcleo central de la teoría de la Constitución, (...) y en la medida que el Estado contemporáneo es el Estado constitucional, el problema de la interpretación es también el problema central de la Teoría del Estado"1. Tan claro está esto hoy en Europa que en base al mismo principio dicho autor sostiene que "La vinculación del juez a la ley se debilita, porque una norma de más alta jerarquía le autoriza a cuestionar su validez o incluso a negarla y a extraer consecuencias necesarias de esta negación, inaplicando la ley que estima inválida o, en el sistema europeo, expulsándola del ordenamiento. El legislador queda desprovisto de instrumentos (al menos legítimos) para contrarrestar la acción del juez y este se alza como el intérprete auténtico de la ley fundamental, por encima del legislador mismo, que no puede actuar sobre la Constitución" ${ }^{2}$.

Todo lo anterior no es sino una de las consecuencias de reconocer el carácter jurídico de la Constitución, y su consecuente obligatoriedad como norma de Derecho, vale decir, el reconocerle el carácter de norma jurídica autoejecutiva, o en jerga procesal, el carácter de lex decisoria

1 En este sentido, Francisco Rubio Llorente, "La interpretación Constitucional", en " $L a$ Forma del Poder, estudios sobre la Constitución", Centro de Estudios Constitucionales, Madrid, 1997, pág. 573 y ss.

2 Id. ant. 
litis, y es en ese orden que entendemos que "El legislador no es un ejecutor de la Constitución, sino un poder que actúa libremente en el marco de esta y esta libre actuación requiere en muchos casos (aunque no, claro es, en todos) que el enunciado de y sus preceptos constitucionales permita un ancho haz de interpretaciones diversas. No de interpretaciones jurídicas, sino de interpretaciones políticas, es decir, de maneras diversas de entender el texto constitucional cuyos enunciados han de construirse, por tanto, con conceptos de valor de un alto grado de abs-

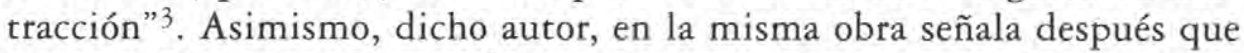
todo conflicto constitucional es, pura y simplemente, el enfrentamiento de dos interpretaciones y que una teoría de la Constitución acorde a las exigencias de nuestra época requiere una concepción material de la jurisdicción, la que difícilmente puede construirse sin una doctrina de interpretación ${ }^{4}$. Todo lo cual nos confirma que, a fin de cuentas, la interpretación de la Constitución, en un sentido existencial, no es otra cosa que su aplicación, y que sin interpretación la aplicación es imposible. Pero en realidad ¿qué es la interpretación constitucional?

Para la pregunta anterior aparentemente podríamos encontrar muchas respuestas, pero muy grande es la desilusión que al respecto hemos sufrido al darnos cuenta de que son muchos los autores que hablan de interpretación constitucional y de cómo, a su juicio, debe ser, pero son muy pocos lo que se atreven a decir qué es la interpretación constitucional y en qué consiste.

No existe hasta la fecha una teoría general de la hermenéutica constitucional (ello sin perjuicio de algunos esfuerzos de autores extranjeros en orden a conceptuar ciertos métodos a los que más adelante nos referiremos), solo tenemos algunas reglas dispersas que la doctrina ha elaborado, y que al no ser generalmente aceptadas aún no son lugares comunes (algunas han sido aludidas alguna vez por los respectivos tribunales), y, en nuestro medio, algunas de las disposiciones de la Constitución que pueden servir como reglas de interpretación. El resto de lo que hay solo es revivir y tratar de adaptar, consciente o inconscientemente, el antiguo y obsoleto método de interpretación de las leyes de Von Savigny, lo cual -a mi humilde juicio- resulta totalmente insuficiente e inapropiado, e incluso, improcedente, toda vez que la Constitución es una norma que, por su finalidad y origen, contenidos y naturaleza, viene enunciada en términos genéricos y abstractos, con referencias valóricas polisémicas y que por ende no son unívocas, por

Id. Ant.

4 En este sentido, valga destacar la pobreza de la doctrina nacional: al hablar de jurisdicción constitucional se aluden los conceptos formales de jurisdicción del Derecho procesal clásico, a lo que se suma la ausencia de una doctrina de la interpretación constitucional lo suficientemente desarrollada. 
lo que su lectura literalista es en la mayoría de los casos inútil para solucionar litigios constitucionales, pues nada dice por sí sola. Así mismo, las materias de que trata y su objetivo de regular el poder y de ser en buenas cuentas el texto del contrato social celebrado por la comunidad para convivir en paz y armonía indefinidamente, hacen que la voluntad originaria del autor no sea relevante, pues hoy el derecho a la autodeterminación (símil posmoderno de la soberanía a mi juicio), es un derecho humano fundamental ${ }^{5}$, por ende irrenunciable, lo cual añade la permanente necesidad de legitimación de la norma constitucional. A ello cabe agregar que el poder constituyente -incluido el derivado- se expresa solo en situaciones especiales, no obstante que el pueblo soberano lo retiene en todo momento, manifestándolo a través de la Carta Fundamental.

Lo antes expuesto hace que la norma constitucional sea radicalmente diferente a la norma legal ordinaria, al tener otros caracteres materiales y otra finalidad, por lo que cualquier interpretación de la misma debe tener presente lo antes expuesto, es decir debe tenerse en cuenta el telos de la norma constitucional. Por todo lo anterior el elemento gramatical muchas veces nada dice, o bien puede decir muchas cosas que hasta pueden contradecirse entre sí (por ejemplo que ha de entenderse por soberanía o por república democrática); el elemento histórico la transforma en un testamento político forzoso de quien la dictó, cercenando al pueblo y a sus representantes el derecho mínimo de pensar e interpretar su constitución dentro de la diversidad del cuerpo político en constante evolución; el elemento sistemático la desnaturaliza pues es la única norma de su jerarquía y al interpretarla a la luz de las otras de menor jerarquía en la práctica pierde su supremacía y pasa solo a ser un trozo de papel con buenas intenciones; y en fin, el elemento lógico en materia constitucional no es tan "lógico" como idealmente debería, por ende de poco sirve, pues al ser la Constitución un verdadero compromiso social, en esta materia usualmente hay en juego valores políticos contrapuestos o al menos difíciles de conciliar por lo que la coherencia de toda carta constitucional es a veces, más un ideal que una realidad (por ejemplo, el art. 4 que proclama a Chile como una República Democrática, o en un ejemplo menos complejo y controvertido, la concepción de Estado subsidiario con el aseguramiento de derechos sociales que requieren de un Estado activo, como el derecho a la salud y a la educación).

Además de todo lo anterior, o quizás por todo lo anterior, el enunciado genérico y abstracto de la norma constitucional hace que

En este sentido ver los arts. $1^{\circ}$ del Pacto Internacional de derechos civiles y políticos y del Pacto Internacional de derechos económicos sociales y culturales. 
para ponerla en ejecución, o -en palabras de R. Dworkin-para darle enforcement, se requiera de un intérprete proactivo, que señale cuál es el significado concreto y tangible del enunciado valórico y genérico de la norma para el caso particular.

En nuestro medio, poco a poco se ha ido constatando el hecho de que la interpretación constitucional es distinta a la legal, y por ende necesita métodos diferentes, o a lo menos, más completos. En este sentido, el profesor Mario Verdugo señala que "desde luego existen, objetivamente, diferencias cualitativas entre la norma común y la norma constitucional:

a) La Constitución es la norma suprema, "la base y unidad de todo el orden jurídico" en donde se encuentran asegurados los derechos humanos individuales y sociales; la creación, forma, competencia y limitación de los órganos que ejercen el poder;

b) Para asegurar la supremacía constitucional se establece un procedimiento especial para su enmienda, a través de esta rigidez -obviamente- se persigue la estabilidad del ordenamiento, al dificultar -a veces en extremo- su reforma;

c) La norma constitucional es también diferente en cuanto a su origen, deriva de la actividad del poder constituyente originario.

En síntesis, la norma constitucional se diferencia de la común por ser superior, por su contenido, por su rigidez y por su origen" 6 .

Esta "reciente" constatación de la doctrina nacional es general en la doctrina comparada, a modo de ejemplo, en el mismo sentido el profesor Verdugo cita a Jorge Carpizo ${ }^{7}$, quien quizás influido por el fuerte contenido histórico y social del constitucionalismo mexicano, afirma categóricamente que "la interpretación constitucional no puede reducirse a tener en cuenta el orden jurídico, sino que factores políticos, históricos, sociales y económicos se incrustan en la vida constitucional de un país y hay que considerarlos". (Carpizo, Jorge "Interpretación constitucional". En Boletín de Derecho Comparado $\mathrm{N}^{\circ}$ 12, 1971, México, p. 384).

Al parecer, ya desechados los obsoletos, incompletos e inapropiados métodos y cánones clásicos y legalistas de interpretación, lo más indicado sería partir por el origen de la interpretación constitucional, es

6 "La interpretación constitucional", Mario Verdugo Marinkovic, Gaceta Jurídica n ${ }^{\circ} 185$, Editorial jurídica ConoSur Ltda. Planteamientos bastante similares pueden encontrarse en obras como Derecho Constitucional Chileno de José Luis CEA EGAÑa, e Introducción al Derecho de Agustín SQuella.

7 Notable constitucionalista mexicano, catedrático y ex rector de la UNAM. 
decir, por el Derecho norteamericano, ya que aproximadamente un siglo y medio antes que los europeos, los norteamericanos le reconocieron a la norma constitucional su carácter de norma jurídica, autoejecutiva y de texto posinterpretativo, lo que significa que mientras este tipo de problemas aparecían en la Europa de mediados del siglo XX, el Derecho norteamericano ya los había reflexionado y en cierta medida resuelto muchas décadas antes.

Antes de entrar en las categorías del Derecho norteamericano, cabe hacer presente su carácter eminentemente práctico, empírico y material, en contraposición a lo teórico y formal que caracteriza al Derecho europeo, diferencias que, obviamente, también se hacen presentes en este tipo de materias.

El profesor Jeffrey M. Shaman, refiriéndose a la interpretación constitucional en un artículo llamado Interpreting the Constitution: the Supreme Court's proper and bistoric function afirma que "el rol de la Corte, cuando todo está dicho y hecho, es, y siempre ha sido, el darle sentido a la Constitución que de otra manera sería un documento vacío (bollow $)^{8 "}$. Así, para los creadores de lo que hoy conocemos como interpretación constitucional, esta sería la creación de su significado: el darle vida al texto constitucional que, por sí solo, no tiene vida.

De lo antes expuesto se debe concluir que lo medular en esta materia es el rol de la interpretación: la Constitución no vive por sí sola como un trozo de papel con unos signos o códigos llamados "letras", que componen una serie de palabras y oraciones, algo que en cuanto creación del hombre no se mueve ni actúa sin la intervención del hombre, que se manifiesta en la interpretación, sin la cual el texto nada dice. Evidentemente, para percatarse de ello, los norteamericanos tuvieron que darse cuenta que la Constitución es una norma de enunciado genérico que, al aplicarla a casos específicos, poco decía para poder resolver la litis teniéndola como el Derecho aplicable, a menos que se entrara a descifrar su sentido y darle desde afuera (por el intérprete), un sentido propio. Prueba de ello es que, hasta hoy, la corriente "originalista" del Derecho constitucional norteamericano discute si la sentencia del juez Marshall, en Marbury con Madison, fue o no ajustada a la Constitución.

En Europa, todo esto no se planteó hasta la segunda posguerra, época en que para el constitucionalismo europeo continental "aparece" como "nuevo" para el derecho continental: la autoejecutividad y la

Jeffrey M. Shaman, "Interpreting the Constitution: the Supreme Court's proper and historic function" en Judicial Politics Reading from Judicature, American Judicature Society, 1992, págs. 37 y siguientes, el autor es profesor de Derecho en la DePaul University. La cita reza "The Court's role, when all is said and done, is, and always has been, to create meaning for a Constitution that would otherwise be a hollow document". 
fuerza obligatoria directa de la norma constitucional frente al resto del ordenamiento. Así, el estudio de la interpretación constitucional en Europa surge en forma mucho más tardía, frente a la nueva necesidad de tener un método para poder aplicar la Constitución en forma uniforme; en efecto, un autor inmerso en dicho contexto, como lo es García de Enterría, escribiendo sobre el tema en los primeros años de vigencia de la Constitución española de 1978, señala oportunamente que "La interpretación constitucional surge como problema jurídico solo cuando la Constitución es entendida como un límite jurídico y no solo político al Poder Legislativo" 9 . En este mismo sentido, García de Enterría nos dice: "Todo el problema de la justicia constitucional enraíza en una cuestión de principio: si conviene o no en reconocer a la Constitución el carácter de norma jurídica", concluyendo que la respuesta es sí, y señalando posteriormente "que en su condición de norma jurídica su eficacia debe ser asegurada jurisdiccionalmente", algo tan evidente -digamos- que, por obvio, suele olvidarse: si se ha estudiado Derecho constitucional por 200 años, es porque la Constitución es norma jurídica, y por ende si se interpreta, ello es directa o indirectamente con la finalidad de aplicarla, de hacerla valer como norma jurídica, es decir, como norma justiciable, cuyo cumplimiento pueda teclamarse ante tribunales, sin lo cual una norma difícilmente puede calificarse de jurídica.

En efecto, la Constitución -como decimos- no puede hablar por sí sola, las palabras que expresa nada dicen si no se conocen los valores políticos que consagra; por ejemplo, tanto una Constitución liberal como una Constitución socialista pueden consagrar la igualdad de las personas como un derecho fundamental, pero el significado de la igualdad de las personas es radicalmente distinto para el pensamiento liberal que para el pensamiento socialista, ocurriendo exactamente lo mismo con los valores que la Constitución consagra y su evolución en el tiempo (por ejemplo, el mismo derecho de igualdad, tenido como fundamental hace ya más de 200 años, no obstante que el concepto de igualdad liberal de inicios del siglo XX no es el mismo que se sostiene hoy, sin que el actual sea menos liberal que el antiguo, y refiriéndose ambos al mismo derecho de igualdad). En efecto, un conocido y difundido autor dice acertadamente: "En ninguna otra rama de la ciencia jurídica tiene mayor aplicación que en el Derecho constitucional el concepto que expusiera Wingmore de que 'las palabras están lejos de ser cosas fijas: son las cosas más fluidas e indefinidas' o el que sentara el Justice Holmes diciendo que 'una palabra no es un cristal transparente e inmutable, es la piel de un pensamiento vivo y puede mudar grandemente de color y contenido

9 Eduardo García de Enterría, La Constitución como norma y el Tribunal Constituciona", Editorial Civitas S.A., Madrid, 1981. 
según las circunstancias y el momento en que es utilizado'. Por otra parte, el contenido teleológico de la norma constitucional ha de ejercer siempre decisiva influencia en su interpretación, que siempre ba de inclinarse en favor de la protección y amparo de la libertad del individuo, así como de la efectividad de valores éticos que juegan dominantemente en el Derecho constitucional, como la justicia, la igualdad, el bienestar general, etc." 10 .

La interpretación de la Constitución ha devenido en algo de tal importancia, que autores europeos de la talla de Jiménez de Parga han llegado a decir que estamos en presencia de un nuevo Derecho constitucional, que se configura con la labor cotidiana de sus intérpretes, que "el nuevo Derecho constitucional considera constituciones vivas"11, que "La tarea de los intérpretes contribuye al establecimiento del nuevo Derecho constitucional, con sus reglas más flexibles, con su contenido judicializado" 12 .

Las nociones de justicia constitucional e interpretación constitucional implican dejar de lado la idea de la Constitución formal como un Código político, pues implica dar por hecho que en ella no está todo, y que no se basta a sí misma, entonces, hay que interpretar y adaptar, hay que recurrir a derechos y valores que erróneamente se les llama "extraconstitucionales" o bien "metajurídicos o metaconstitucionales", y a los que nosotros preferimos denominar como Derecho constitucional material jurisprudencial o no escrito ${ }^{13}$, que pasa a explicitarse en la Constitución por vía jurisprudencial, a través de tribunales que los vinculan y conectan con el genérico texto de la Constitución escrita, y el significado de los valores políticos que contiene. Así hoy las constituciones son abiertas, y se habla de la creación de normas o la creación de Derecho constitucional por los tribunales constitucionales ${ }^{14}$. Aunque parezca demasiado insistente, esto es nuevo para el Derecho europeo y los países receptores de su influencia, pero en Norteamérica llevan casi doscientos años hablando de los implicit powers que tiene la Corte Suprema por vía de interpretación constitucional a este respecto.

10 Linares Quintana, Segundo Reglas para la Interpretación Constitucional. Ed. Plus Ultra, Buenos Aires, 1987.

11 Manuel Jiménez de PARGA, en el prólogo de Formación de la Constitución y Jurisdicción constitucional, de José Acosta Sánchez, Ed. Tecnos, 1998.

12 Id. ant.

13 En efecto, este derecho material jurisprudencial o no escrito no es otra cosa que el significado de esos valores políticos contenidos en el aspecto material del texto constitucional, por ejemplo cuando consagra la "igualdad ante la ley", la "soberanía popular" o la "libertad personal" entre otros valores de naturaleza política que la Constitución hace derecho.

14 En este sentido Formación de la Constitución y jurisdicción constitucional, de José Acosta SÁNCHEZ, Ed. Tecnos, 1998. 
Entonces, en un primer approach, podemos señalar que la interpretación constitucional es la producción del sentido del texto constitucional, al aplicarlo al caso concreto, para salvaguardar la supremacía de la Constitución. Ello, partiendo de la base, ya señalada, de que la Constitución no tiene vida si no se la interpreta. Como dice el profesor Ismael Bustos, cuando se redacta una Constitución, es porque existe la intención de aplicarla. Pero esta aplicación supone el comprenderla, y esta comprensión, a su vez, exige la previa interpretación ${ }^{15}$. Así, la interpretación de la Constitución es una herramienta al servicio de su aplicación, que a su vez constituye idealmente el primer medio de resguardo de la supremacía constitucional, de modo que la interpretación puede ser el método para salvaguardar la Constitución, como también, por desgracia, para destruirla (como, por ejemplo, la Constitución de Weimar o el Estatuto Albertino) según cual sea la intención que se busca al aplicarla, en lo cual se manifiesta la tremenda importancia de esta materia y del criterio con que debe abordarse.

Ahora, ¿cómo comprendemos y, en consecuencia, cómo interpretamos? Siguiendo al mismo Ismael Bustos (en la misma obra ya citada), además del texto hay que interpretar el contexto, para lo cual hay que comprender y, aún más, compartir los valores políticos que se expresan en el orden jurídico a través de la Constitución; porque, si no se es parte de ellos, ¿cómo podrá lograrse una interpretación coherente o consistente? A nuestro juicio, esta interrogante planteada por el profesor Bustos puede tener dos respuestas: una desde la teoría democrática, respuesta que es evidente: si la Constitución es democrática, evidentemente que solo el demócrata podrá interpretarla genuina o auténticamente. La otra respuesta se da en el caso de la Constitución no democrática, es decir, autocrática, porque aunque no se comparta ni el origen ni los valores no democráticos, la legítima y auténtica interpretación de una Constitución es y será siempre (o mejor dicho debería ser siempre) la que emane del cuerpo político (y sus órganos). En este caso de Constitución no democrática, es el mismo cuerpo político el que no participa ni de los valores ni de la génesis de dicha Constitución, no obstante ser el destinatario de ella, por lo que, de todas formas, será obligado y regulado por dicha norma. A pesar de ello, e independiente del carácter de la Constitución que rija al cuerpo político, este tiene siempre el derecho a darse su propia norma fundamental que consagre los valores políticos

15 Ismael Bustos Concha, "La Constitución, su interpretación y la justicia constitucional", en La Revista de Derecho, Universidad Central, abril de 1991, número dedicado a las $2^{a}$ Jornadas de Derecho Procesal Constitucional, págs. 59 y sigs. Posteriormente, en la misma obra, el profesor Bustos observa que, a fin de cuentas, "interpretación" y "aplicación" son solo dos aspectos formales de un solo proceso. 
que profesa, es decir, conserva siempre el poder constituyente originario, concebido en la actualidad como un derecho fundamental ${ }^{16}$.

A la luz de lo anterior, ¿implica entonces la interpretación constitucional una valoración política? Evidentemente sí. En un análisis del trabajo de don Ismael Bustos citado anteriormente, el profesor Domingo Hernández Emparaza señala que existe una verdadera ideología de la interpretación constitucional, que dicha interpretación cumple finalidades políticas, porque se basa en valoraciones políticas, señalando que los valores de la Constitución son el compromiso ideológico del intérprete, que detrás de toda categoría jurídica existe subyacente una concepción política que inspira también los códigos tradicionales ${ }^{17}$.

¿Será quizás esta, una de las principales dificultades para lograr llegar a una teoría general y única de hermenéutica constitucional?

Nos inclinamos por señalar que sí, y al parecer no somos los úni$\cos \mathrm{ni}$ es esto algo tan nuevo como pudiera parecer. En efecto, ya hace aproximadamente veinte años un constitucionalista polaco universalmente reconocido, el profesor Jerzy Wroblewski, señaló en este orden de cosas que la Constitución es un acto a la vez político y jurídico y que se puede señalar que cada regla de Derecho es política por razón de las mismas características propias del Derecho constitucional, y que aquí importa subrayar que la Constitución es un acto normativo con un carácter político especialmente pronunciado ${ }^{18}$. Es así que aparece de manifiesto el carácter político-ideológico de la interpretación constitucional, al punto que "el intérprete tropieza aquí y allá con teorías, conceptos, ideas que no tienen significado cierto, unívoco, con la precisión convencional de los científicos" ${ }^{19}$. Resulta así claro, que además de una teoría general de la hermenéutica, necesitamos conocer y uniformar la Teoría de la Constitución en sus aspectos materiales, que es claramente el elemento político de toda esta cuestión.

Independientemente de este primer approach "politológico" o más bien "politicista" (por llamarlo de alguna forma que permita dar a entender su perspectiva desde el Derecho político), debemos analizar el concepto de interpretación o hermenéutica constitucional como parte o rama de una teoría general hermenéutica. La razón es muy sencilla: si no conocemos la interpretación ni la disciplina encargada de su estudio,

16 En este sentido, ver art. 1 del Pacto Internacional de derechos civiles y políticos".

17 Domingo Hernández E. "la Constitución, su interpretación y la justicia constitucional", en La Revista de Derecho, Universidad Central, abril de 1991, número dedicado a las $2^{\text {as }}$ Jornadas de Derecho Procesal Constitucional, págs. 65 y sigs.

18 WROBLEWSKI, Jerzy, el autor expone y desarrolla este tópico entre otros en Constitución y Teoría General de la Interpretación Jurídica, Ed. Civitas, Madrid 1985.

19 Luis Carlos SaChica, el autor expone sus tesis a este respecto en El Control de la Constitucionalidad. Ed. Temis, Colombia, 1988. 
mal podremos saber en qué consiste la hermenéutica constitucional. Así que quien hable de "hermenéutica constitucional", primero debe saber qué es la hermenéutica, y luego aplicarlo a la Constitución. Es por lo anterior que no habrá consenso ni menos un concepto unívoco de interpretación constitucional sin una teoría general hermenéutica, la que hasta ahora es muy difícil conceptuar.

\section{Conceptos fundamentales para una teoría general herme- NÉUTICA Y SU RELACIÓN CON LA CONSTITUCIÓN}

Para el profesor Ismael Bustos, interpretar es revivir e interrogar un texto (no un autor), y no se lee un sentido sino un texto; la lectura produce un sentido, no lo reproduce, cada lectura es la producción de un nuevo texto: es un nuevo texto sobre un texto anterior, y toda lectura es una producción ("pro-ducto", o mejor, "pro ducere"); no una re-producción o repetición de sentido. Entonces, para interpretar la Constitución debemos interrogarla, para producir un sentido que le adscribamos a ella reviviéndola; porque como todo texto, la Constitución es solo un texto muerto, que sin interpretación (comprensión) nada dice a nadie.

Según el Diccionario de Filosofía de bolsillo de José Ferrater Mora (Alianza Editorial, Barcelona, 1987), la voz "hermenéutica" viene del griego, y significa primariamente "expresión (de un pensamiento)"; de abi, explicación y, sobre todo, interpretación del mismo.

Siguiendo a Gadamer, comprender es interpretar. Comprender es reconocerse parte de la historia de lo que se quiere comprender y supone participar en el sentido histórico de la cosa misma en cuanto ha producido efecto histórico. La comprensión es la fusión de dos horizontes: el del intérprete y el del texto ${ }^{20}$, ¿será el producto de la interpretación, entonces, la síntesis de esos dos horizontes? a nuestro parecer así debiera ser.

Así, cabe concluir que la comprensión de la Constitución no es otra cosa que su interpretación, la comprensión de ella en su aspecto diacrónico y en su aspecto sincrónico como producto del anterior, a través de la fusión del horizonte interpretativo del hermeneuta y el horizonte del texto, texto que como tal está muerto y que es revivido por el intérprete al fusionarlo con el suyo y de esa forma comprenderlo. Para esto debemos conocer la historia de la Constitución, y asumirnos como inmersos en ella, para fusionarla con nuestro horizonte (historia, tradición y lenguaje) y así llegar a la interpretación de ese conjunto

20 A este respecto, ver "Curso de Ética y Filosofía del Derecho" Ismael Bustos Concha, Facultad de Ciencias Jurídicas y Sociales, U. Central, 2003. 
de valores políticos que se asumen como Derecho, a través del nombre de Constitución.

Dilthey nos señala que lo que se interpreta es la "expresión" del hombre en sus obras, que la historicidad y la temporalidad son dimensiones inherentes a la comprensión, porque la naturaleza del hombre no es estática sino histórica, y la experiencia se realiza en la temporalidad. Además, nos señala que el sentido es contextual: el todo le da sentido a las partes y las partes son las que hacen al todo, que la interpretación se remite a la situación actual del intérprete (por su historicidad), y que comprendemos solo por referencia a nuestra experiencia, impregnada de historicidad, lo que impregna también a nuestra comprensión ${ }^{21}$. Así la Constitución se interpreta como una institución: una creación del hombre para satisfacer necesidades sociales (políticas, en este caso), que, por lo mismo, es eminentemente dinámica. Al evolucionar las necesidades a satisfacer, se interpreta a la luz de su evolución (historicidad), y de su contexto. Porque el texto no puede entenderse sin su contexto, la Constitución no es interpretable sin comprender la actualidad en la que está inmersa: las situaciones que ha de regir, la realidad política en la cual se desenvuelve, etc., las otras partes de ese todo del cual la Constitución también es parte, que a la vez constituyen la "experiencia" de la Constitución, todo ello combinado con la historia del intérprete, que condiciona su horizonte interpretativo, y por ende los resultados de su interpretación, siguiendo al profesor I. Bustos, "es su contexto político el que le da sentido a la Constitución, y no a la inversa; como, asimismo, no es que los valores políticos suyos hayan de interpretarse a la luz de las normas jurídicas, sino al revés" 22 ; a nuestro juicio, entonces, es la historicidad la que le da su ser a la Constitución. En este orden de cosas, el muy desarrollado Derecho constitucional jurisprudencialinterpretativo norteamericano (o Derecho constitucional paralelo como lo llaman ellos mismos), por llamarlo de una forma que lo distinga del Derecho constitucional escrito, ha agregado otra teoría más (distinta de los implicit powers y el self restrict) a los factores que se deben tener en cuenta para interpretar la Constitución, en la que a nuestro juicio se recogen, o al menos se contienen, todas estas observaciones respecto del contexto: la teoría del llamado American Legal Realism, algo que en castellano se ha traducido como "realismo jurídico" 23 , y que no es otra cosa que vincular a la Constitución con el proceso político actual al

Id. ant.

22 Ismael Bustos Concha, "La hermenéutica constitucional", Revista de Derecho, Universidad de Valparaíso, 1986.

23 José Acosta Sánchez, Formación de la Constitución y jurisdicción constitucional, Ed. Tecnos, Madrid, 1998, págs. 134 y 135. 
que va a normar, el considerar el proceso político y la realidad misma como una de las variables dentro de la interpretación, y más aún, como una condicionante de ella.

Por otra parte, y en el mismo sentido, el profesor Ronald Dworkin nos dice que los jueces no pueden discrepar sobre qué palabras hacen de la Constitución un texto preinterpretativo; el desacuerdo viene en lo que la Constitución es como texto posinterpretativo y que, de la misma forma, los jueces no pueden ser divididos entre los que obedecen a la Constitución y los que no, porque esta distinción ignora el carácter filosófico del Derecho como interpretación, acorde con el cual cada juez es un intérprete, que trata de imponer su mejor interpretación ${ }^{24}$, así nadie discrepa sobre qué palabras están escritas en los artículos de las hojas del papel del texto constitucional, el problema radica entonces en qué significan y qué nos dicen esas palabras.

Lo anterior debemos concordarlo con lo que posteriormente nos dice a propósito de lo que para nosotros es el horizonte del intérprete: "En orden a leer la Constitución de la mejor forma, los argumentos de Hércules ${ }^{25}$ abrazan las convicciones populares y las tradiciones nacionales y -al fin pero no al menos-sus propias convicciones sobre justicia y fairness en las relaciones recíprocas" 26 . Además de todo lo anterior, "Hércules escapa a los estándares académicos de clasificación de jueces; él no piensa que la Constitución es solo lo que teórica y abstractamente se enseña, él cree que la Constitución consiste en la mejor interpretación available (alcanzable) del texto y su práctica como un todo, cuya interpretación es también sensible respecto de la complejidad de los valores políticos (political virtues) conexos con el tema"27. Además, como dice el propio Dworkin, los jueces tienen su propio interés personal e ideológico en el resultado de los $\operatorname{casos}^{28}$, lo cual podría resultar algo gravísimo para nuestra mentalidad jurídica continental, pero que no tiene en realidad nada de extraño para Dworkin, sobre todo considerando que el juez es un ciudadano, que en Estados Unidos es, en ciertos casos, electo popularmente, y que muchas veces resulta elegido porque

24 Ronald Dworkin, "Law's Empire", London, Fontan Press, 1990, pág. 360, citado en "A new approach to constitutional justice: profesor Dworkin's, An interpretative analysis about an interpretative approach", Ismael Bustos CONCHA, XXIV Jornadas Chilenas de Derecho Público, Santiago 1993. El presente trabajo está escrito en inglés, la traducción de esta cita es nuestra, todas las notas sobre Ronald Dworkin en esta memoria se extraen de él. Sin perjuicio de lo anterior, el profesor Ismael Bustos ha traducido dicho trabajo, y ha sido publicado como parte la última edición de su Manual de Ética y Filosofía del Derecho, citado en otras partes del presente trabajo.

25 Figura imaginaria de un juez omniconsciente y omnipotente.

26 DwORKIN, ob. cit., p. 398.

27 Idem, ob, cit., p. 399.

28 Idem, ob. cit., p. 375. 
dice públicamente "soy republicano" o "soy demócrata". Aquí, todo esto, evidentemente, nos hace volver al problema de la legitimidad: si este es el aspecto ideológico y coyuntural de la justicia constitucional, aspecto que podría llegar a ser cuestionable, en realidad un análisis más acabado permite sostener con razón y claridad que el contrapeso de dicha "cuestionabilidad" va por la generación de los integrantes de los tribunales llamados a aplicar la Constitución: la existencia de legitimidad democrática en la integración de dichos tribunales, el procedimiento democrático para el nombramiento, la posibilidad de hacer efectivas responsabilidades, la representatividad emanada del cuerpo político, etc., todo ello en orden a una finalidad específica: la salvaguarda de la norma fundamental llamada Constitución, lo que no puede comprenderse si no se asumen todos los aspectos de la norma constitucional; quizás por eso que en Estados Unidos los llamados originalistas critican a los jueces de la Corte Suprema diciendo que son designados "a dedo", porque la regla general, con el resto de la judicatura, es por elección popular o bien por otros procedimientos que, indiscutiblemente, son bastante más democráticos y participativos que la designación "a dedo", lo que trae como consecuencia que, en ciertos estados, exista el llamado recall (revocación) en contra de los jueces.

Al parecer, por obvio se olvida que el intérprete interpreta según su propio horizonte; y, si es ese el problema, la solución es muy simple: los procedimientos de la democracia, en la generación del órgano intérprete de la Constitución, permiten que el horizonte del intérprete se ajuste a los de la comunidad; entonces, la solución no es otra que democratizar procedimentalmente la generación de la judicatura constitucional, y someterla al control propio de la democracia en el ejercicio de sus funciones, para que vele por esta en los aspectos de fondo, a través de sus decisiones.

Con todo lo anterior, nos queda más que claro que la hermenéutica constitucional es el punto cúlmine de la justicia constitucional, pues a través de ella se realiza dicha justicia (o se lleva a la práctica la actividad jurisdiccional relativa a ella si la palabra "justicia" no agrada) para casos concretos, lo que significa aplicar la Constitución al caso, a su época, a sus condiciones, etc., i.e. adaptarla al contexto y al todo en el que está inmerso el caso a resolver desde los valores políticos del texto, que para nosotros no son otros que los de la democracia. En este sentido, es muy obvio el juicio de García de Enterría, al señalar, entre las funciones políticas más importantes del Tribunal constitucional, la de una interpretación evolutiva que adapte el texto de la Constitución a las situaciones históricas cambiantes, tras lo cual señala que, así, la apertura del sistema político y el respeto por las minorías son más posibles cuando son aseguradas por un Tribunal constitucional como intérprete de una Constitución democrática, que cuando dependen del 
arbitrio de la buena voluntad del partido en el poder en ese momento ${ }^{29}$. Al parecer la analogía de todo esto con la experiencia de Weimar es innegable, pues en dicho caso, se estaba en frente de una de las constituciones más avanzadas y democráticas de su momento, pero sin una efectiva justicia constitucional que realizara la tarea hermenéutica que hemos enunciado. Así los derechos de la minoría, y después los de todos los alemanes, dependieron del partido mayoritario de ese momento, que manejó la Constitución a su conveniencia y según sus intereses particulares sin contemplación de los que no estaban en el partido y los que podían llegar a estar contra dichos intereses.

Volviendo a la idea anterior, en ese orden el profesor Acosta Sánchez señala, entre los tres fines básicos de lo que denomina jurisdicción constitucional ${ }^{30}$, el garantizar las libertades y los derechos fundamentales. A nuestro juicio, esta idea surgida de la Europa de la segunda posguerra es la fundamental respecto de la actual justicia constitucional que, sin perjuicio de versar también sobre aspectos orgánicos de la Constitución, es más que todo, justicia de derechos fundamentales, justicia de subordinación de los poderes públicos ante estos; y es esa otra razón más para usar el término "justicia" y no "jurisdicción", porque, al ser los derechos fundamentales algo material y que va más allá de la Constitución formal, lo relevante deja de ser ya el conjunto de aspectos formales, dentro de los cuales está el concepto de jurisdicción y sus elementos. En efecto, si a un jurista inglés o a un jurista norteamericano le preguntamos por la jurisdicción constitucional en sus respectivos países, probablemente nos preguntarán qué es eso, ya que conceptos teórico formales de este tipo no tienen cabida en su derecho, y nos contestarán después que solo conocen la revisión judicial, el Bonham case, y la facultad de la Corte Suprema de interpretar la Constitución, y que para saber más hay que ver los casos. A este respecto, los norteamericanos suelen hablar de "Constitutional adjudication", señalando que obviamente no es un proceso mecánico, y que requiere apelar a la razón y la discreción ${ }^{31}$, a lo que además se suma la doctrina del American Legal Realism, que plantea prescindir de todo formalismo que pretenda dejar de lado la

29 Eduardo García de Enterría, "La posición jurídica del Tribunal Constitucional en el sistema español: posibilidades y perspectivas", Revista Española de Derecho Constitucional, $\mathrm{N}^{0} 1$ volumen 1, enero-abril de 1981.

30 Los otros dos son "depurar el ordenamiento de normas inconstitucionales" y "arbitrar conflictos de competencia". A ellos cabe agregar lo que dicho autor denomina "los tres fines no escritos", a saber, "la participación en el proceso legislativo", "la creación de normas constitucionales" y "la constitucionalización de todas las ramas del derecho".

31 "Constitutional adjudication is obviously not a mechanical process. It requires an appeal to reason and discretion", Edwin MESSE III, en Interpreting the Constitution, varios autores, Northeastern University Press, Boston, 1990, pág. 17. El autor era en ese momento Ministro de Justicia de los Estados Unidos. 
vinculación entre derecho y política, entrando de lleno en los aspectos de fondo de los casos constitucionales ${ }^{32}$.

En efecto, este nuevo Derecho constitucional supera las teorías generales y pasa a ser inductivo: del caso particular resuelto surgen una serie de normas que pasan a ser parte de la Constitución o como se señala hoy, Derecho constitucional material, en definitiva lo que los norteamericanos muchos años llamaron el proceso constitucional continuo, a propósito de la labor de su Corte Suprema en su sistema político.

Todo eso que, en los Estados Unidos ${ }^{33}$ está tan claro, en Europa recién emerge hace poco tiempo y, al parecer, los europeos (salvo ingleses y alemanes, por razones históricas) no ven con buenos ojos la tremenda carga política o ideológica de la justicia constitucional o, al menos, tienen prejuicios muy marcados a este respecto, por lo cual muchas veces recurren a análisis más formales que materiales respecto del tema, quizá para eludir los aspectos políticos. En este sentido, Rubio Llorente advierte que "la vinculación del juez a la ley se debilita, porque una norma más alta le autoriza a cuestionar su validez o incluso a negarla y a extraer consecuencias necesarias de esta negación, inaplicando la ley que estima inválida $o$, en el sistema europeo, expulsándola del ordenamiento. El legislador queda desprovisto de instrumentos (al menos, legítimos) para contrarrestar la acción del juez y este se alza como intérprete supremo de la ley fundamental, por encima del legislador mismo, que no puede actuar sobre la Constitución" 34 aludiendo a lo formal más que a los aspectos de fondo, a pesar de reconocer que los Tribunales constitucionales son órganos políticos y jurídicos, aunque señale que el componente político viene dado solo por ser políticos los órganos cuya actuación controlan y revestir eventualmente trascendencia política sus propias decisiones ${ }^{35}$. Todo esto deja de manifiesto el approach más bien formal al tema, eludiendo e incluso negando a ratos el carácter político del fondo de la cuestión. Quizás García de Enterría aborda más frontalmente los aspectos políticos, pero también recurriendo a la forma, asume que el conflicto a resolver es un conflicto político (algo

32 En este sentido, ver José Acosta SánCHeZ, Formación de la Constitución y jurisdicción constitucional", Ed. Tecnos, Madrid, 1998, págs. 134 y 135.

33 A este respecto, en dicho país se habla comúnmente de Judicial Politics y Judicial activism, en efecto, uno de los libros tenidos a la vista para el presente trabajo se llama "Judicial politics: reading from judicature", que, traducido su título, reza "Política Judicial: Lecturas extractadas de la judicatura" (nótese que el término usado es politics, no policy), editado por una sociedad de jueces.

34 Francisco Rubio Llorente, "Seis tesis sobre la jurisdicción constitucional en Europa", en La Forma del Poder, estudios sobre la Constitución", Centro de Estudios Constitucionales, Madrid, 1997.

35 Id. ant. 
más claro que lo anteriormente visto), pero dice que la resolución del mismo se hace en base a criterios y métodos jurídicos ${ }^{36}$; lo cual puede ser muy cierto respecto del procedimiento para solucionar el conflicto (claramente derecho procesal, sea procesal constitucional o constitucional procesal), pero la lex decisoria litis, no es otra que el contenido de la Constitución: los valores políticos que contiene y su concreción práctica a través de los poderes constituidos que la Carta Fundamental estatuye, y los "derechos" fundamentales que consagra, que al recogerse en la Constitución pasan a ser derecho, pero que ante todo ( $y$, por ende, antes de ser derecho) son valores políticos, que después se "juridizan" al pasar a ser derecho, o mejor dicho, en palabras del profesor Ismael Bustos C., "los valores políticos constitucionalizados"37; así, volvemos a la clásica y clara premisa: formalmente, la Constitución es una ley (ley superior), y materialmente no es otra cosa que un conjunto de valores de naturaleza política que se recogen y escriben en esa ley fundamental, por lo que en términos materiales la solución será siempre política.

Pero a pesar de las citas del párrafo anterior, los reconocidos autores españoles aludidos dejan entrever la gran importancia del fuerte carácter político de la justicia constitucional. Rubio Llorente, desde la perspectiva de los conflictos constitucionales entre los órganos del Estado, afirma que "el legislador no es un ejecutor de la Constitución, sino un poder que actúa libremente en el marco de esta, y esta libre actuación requiere en muchos casos (aunque no, claro es, en todos) que el enunciado de esos preceptos constitucionales permita un ancho haz de interpretaciones diversas. No de interpretaciones jurídicas, sino de interpretaciones políticas, es decir, de maneras diversas de entender el texto constitucional cuyos enunciados han de construirse, por tanto, con conceptos de valor de un alto grado de abstracción" 38 . El mismo autor, en la misma obra, observa después que "todo conflicto constitucional es pura y simplemente el enfrentamiento de dos interpretaciones" y que "una teoría de la Constitución acorde a las exigencias de nuestra época requiere una concepción material de la jurisdicción, la que difícilmente puede construirse sin una doctrina de interpretación". Todo lo señalado por Rubio Llorente nos confirma que, realmente, la interpretación de la Constitución no es otra cosa que su aplicación, ello porque en la aplicación de toda norma (en este caso la Constitución), va ínsita (contenida) la interpretación de la misma. Así lo señalado, ya debemos

\footnotetext{
36 Eduardo García de EnTERría, La Constitución como norma y el Tribunal Constitucional, Editorial Civitas S.A., 1991, pág. 178.

37 Ismael Bustos Concha, "Introducción al análisis de la Justicia Constitucional”, en Anuario de Filosofía Jurídica y Social, año 1989.

38 Francisco Rubio Llorente, "La interpretación Constitucional", en La Forma del Poder, estudios sobre la Constitución, Centro de Estudios Constitucionales, Madrid, 1997.
} 
tener muy en claro que sin interpretación la aplicación es imposible, y que sin perjuicio de lo que Rubio Llorente pueda señalar respecto de los aspectos políticos de los conflictos de constitucionalidad, estos conflictos en verdad son de interpretación, señalando el propio autor citado que "el texto debe permitir varias interpretaciones" -y aquí va lo interesante- "interpretaciones políticas, no jurídicas". Así para nosotros queda claro que el conflicto es, entonces, político.

A propósito del caso español, en que la Constitución declara expresamente los derechos fundamentales como "valores superiores del ordenamiento", García de Enterría advierte que ello constituye una posición dominante y, por ello implica, la posibilidad de declarar, de calificar, desde esos valores superiores, como "inconstitucionales" normas actuales o futuras (ello, siguiendo tesis alemanas, según el propio autor lo señala), por lo cual la eficacia de la Constitución ha pasado a ser la eficacia de los derechos fundamentales ${ }^{39}$.

"La diferencia obvia entre un juez constitucional y el juez ordinario es que los valores en que ha de buscar su juicio el primero son, en primer término, los valores políticos decididos por el constituyente, en tanto que el segundo son simples valores civiles, penales, laborales, etc." 40 . Para el profesor Ismael Bustos, estos valores políticos a que debe sujetarse el juez constitucional, aparecen como explícitos, manifiestos o patentes (no latentes), mientras que los valores a los cuales debe sujetarse el juez ordinario son también en realidad valores políticos, pero que, a diferencia de los anteriores, aparecen como supuestos, presupuestos, implícitos, latentes (no patentes), que aparecen explicitados como valores civiles, penales, etc. ${ }^{41}$.

Para Rubio Llorente, la norma constitucional es estructuralmente distinta de la norma legal ordinaria; tiene un grado de generalidad y abstracción mayores por lo cual la "voluntad objetiva" y los supuestos de hecho de la norma no existen, o existen solo como principio, en los casos importantes, que son los de derechos fundamentales. Por ello, deben ser determinados por el intérprete, con lo cual la labor del juez constitucional es mucho más creadora que la del juez ordinario. El juez constitucional crea normas constitucionales (como derivación de "un derecho más alto cuyo sentido solo él puede precisar") que, por ser tales no pueden ser modificadas ni desconocidas por el legislador. Es por todo lo anterior que no resulta extraño que este autor señale,

39 Eduardo García de Enterría, "La posición jurídica del Tribunal Constitucional en el sistema español: posibilidades y perspectivas", Revista Española de Derecho Constitucional, $\mathrm{N}^{\circ} 1$ volumen 1, enero-abril de 1981.

40 Id. ant.

41 Nota del profesor Ismael Bustos CONCHA. 
en el mismo trabajo, que la trascendencia política de las sentencias constitucionales no está tanto en el sentido de la decisión como en el razonamiento por el cual se llega a ella ${ }^{42}$. A nuestro entender, aquí aparece de manifiesto el carácter general y abstracto de la norma constitucional, que para mayor entendimiento, interpretación y aplicación debe ser "concretizada", lo que significa que el intérprete y aplicador debe idear una adaptación al caso particular, que la norma constitucional no alude directamente, todo lo cual no es otra cosa que la creación de normas constitucionales específicas a partir de lo que formalmente se entiende por Constitución, con la finalidad de llevar a la práctica su fuerza normativa y el principio de la supremacía constitucional. Es de ese orden el aporte de Marbury con Madison: si el juez encuentra una ley específica que dirime expresamente la litis, pero que va en contra de la norma enunciada genéricamente por la Constitución, debe fallar en contra de esa ley, ya que la jerarquía superior de la Constitución se impone y, por otro lado, la validez de la ley cae por su propio peso.

En este sentido, si bien el Derecho europeo ha avanzado mucho, aún no es comparable en estos aspectos con el Derecho norteamericano. En efecto, ello quizás será por estar más preocupados de la práctica que de las teorías de tratadistas, y por dicha razón frente al mismo problema planteado, el de la politicidad de la interpretación constitucional, la respuesta norteamericana es radicalmente distinta: la doctrina del American Legal Realism, que "profundiza el ataque contra el empeño del pensamiento ortodoxo de crear un sistema para la separación del Derecho y la política" ${ }^{33}$, ello partiendo de la base que el Derecho ha perdido el contacto con la realidad, según los autores norteamericanos (en este sentido se cita a Morton Horwitz).

\section{UNA METODOLOGÍA DE LA INTERPRETACIÓN CONSTITUCIONAL: TAREA PENDIENTE}

Ya nos hemos referido al vacío en este tema y a que es común hablar de "interpretación constitucional", pero casi nadie osa en esbozar una teoría general ni menos un método acerca de ella.

Esta falencia, general en el derecho comparado ${ }^{44}$, se agudiza aún más en la doctrina nacional, donde la circunstancia ya señalada es casi

\footnotetext{
42 Francisco Rubio Llorente, "La interpretación Constitucional", en La Forma del Poder, estudios sobre la Constitución, Centro de Estudios Constitucionales, Madrid, 1997.

43 José Acosta Sánchez, Formación de la Constitución y jurisdicción constitucional, Ed. Tecnos, Madrid, 1998, págs. 134 y 135.

44 Esta conclusión no es aventurada ni mucho menos propia, en su libro Por una Teoría jurídica del Estado, Michel Troper arriba a la misma conclusión en la pag. 273: "Los muy escasos
} 
universal, por lo que a este respecto no cabe sino recurrir a autores extranjeros, en que tampoco hay mucho a este respecto.

Un problema de esta envergadura no deja de ser importante, sobre todo tras constatar que "le es posible al juez constitucional crear normas constitucionales, precisamente, desde su libertad de elegir el método" 45 , más aún si, en palabras de Triepel, "El Derecho constitucional, como cualquier otra rama juridica, exige un método interpretativo específico, para servir a la función y la esencia de los valores propios de ese ámbito jurídico", el problema radica en que, hasta hoy, no se ve un método interpretativo específico, y además, generalmente aceptado, como el que alude $H$. Triepel.

En efecto, existen algunos "métodos" y "modelos" de interpretación constitucional, pero ninguno generalmente aceptado, lo que por bien planteados que estén, los hace estériles.

Dentro de los mismos modelos o métodos, existe una verdadera diáspora jurídica, y dentro de ella podemos señalar los siguientes ${ }^{46}$ :

a) Método jurídico o hermenéutico clásico, que no constituye otra cosa que revivir y aplicar a esta rama del Derecho el pensamiento hermenéutico de Savigny, lo que no viene al caso conforme ya se analizó.

b) Método tópico-problemático, fundamentado en el pensamiento tópico de Theodor Viehweg, pone a la interpretación como una disciplina práctica en el centro de todo al problema a resolver y concibe a la norma constitucional como algo abierto, fragmentario e indeterminado, en definitiva un texto dialéctico, no apodíctico, por lo que en definitiva la interpretación nos llevaría a un proceso de discusión y argumentación que parte desde los “topoi”, lugares comunes o puntos de vista comúnmente aceptados, a fin de llegar, desde la polisemia de la norma constitucional, a la interpretación más conveniente al problema mediante el uso de los tópicos relativos a ella. A mi juicio, este método da un gran aporte: el uso de la argumentación práctica y su orientación hacia un claro fin: la solución del problema constitucional. Como contrapartida en esta

autores que han intentado tratar el problema de la interpretación en Derecho constitucional han debido constatar que no tenían predecesores (...) los tratados o manuales de Derecho constitucional parecen mostrarse relativamente indiferentes ante esta cuestión".

45 José Acosta Sánchez, Formación de la Constitución y jurisdicción, Ed. Tecnos, Madrid, 1998, p. 375 .

46 El presente "catastro" está extraído del artículo "Tendencias contemporáneas en la interpretación constitucional", del profesor Francisco ZúÑIGA URBINA, publicado en el libro Interpretación, Integración y Razonamiento Jurídico, Ed. Jurídica de Chile, 1992. Cabe destacar lo completo y sistemático de dicho trabajo. 
materia el partir solo de lugares comunes puede, en situaciones de crisis, llegar a debilitar todo lo que se pueda hacer, además que la norma constitucional puede verse disminuida por la casuística y las consideraciones coyunturales, lo que atenta en contra de su finalidad.

c) Método hermenéutico-concretizador, ideado por Konrad Hesse, es quizás lo más cercano a los principios generales de hermenéutica ya aludidos; en efecto este método recoge los conceptos relativos al horizonte, tiene en cuenta el contexto, conceptualiza los prejuicios y la precomprensión, y por la vía de la hermenéutica concretiza al caso particular el significado del texto constitucional, que por sí solo nada dice y que es un texto preinterpretativo, abierto e incompleto cuando no media interpretación del mismo, necesitado entonces de "concretización", que sería entonces la tarea del intérprete.

d) Método científico-espiritual o valorativo-sociológico: se debe tener presente el conjunto de valores inmersos en la constitución, los que deben comprenderse y aplicarse como medio de integración colectiva de la sociedad por el intérprete. Este método se basa en la obra del publicista alemán Rudolf Smend.

e) Método normativo-estructurante: método basado en la obra del alemán Friedrich Muller, parte de la base que se debe interpretar con el tenor literal de la norma y la investigación del "referente normativo", la estructura de la norma, atribuyéndole al precepto un carácter de "programa normativo". Como crítica cabe señalar que en este caso la interpretación no sale del marco dado por la norma y no recibe nada externo, lo que, en sus consecuencias, lo hace bastante similar al método de Savigny, en los términos recogidos por el Código Civil.

f) A lo anterior cabe agregar la sistematización de reglas y elementos propuesta en su obra ya citada por Segundo Linares Quintana: teleológica, práctica, semántica, sistemática y progresista, además de la regla de la razonabilidad, el sentido restringido de privilegios y excepciones y la presunción de constitucionalidad

A este respecto, cabe citar a Acosta Sánchez, en su obra ya citada, en la que acertadamente alude a la "inexistencia de métodos de interpretación constitucional vinculantes" (la cursiva es nuestra), además de la imposibilidad de establecerlos y que, en consecuencia, a su juicio, "lo único que existe en la vastedad del problema son dos límites muy lejanos entre sí y un inmenso campo intermedio" ${ }^{47}$, límites que, a jui-

José Acosta Sánchez, ob. cit., págs. 373 y ss. 
cio de este autor, están por un lado en la teoría de la interpretación como acto de conocimiento y por otro, en la teoría de la interpretación como acto de voluntad, modelos que, de una u otra manera, permitirían abarcar los diferentes métodos y reglas.

Asimismo, la teoría de la interpretación como acto de conocimiento, señala que la interpretación no sería otra cosa que "la descripción científica del significado de un texto tras un proceso lógico de extracción" 48 , teoría que critica, crítica a la cual adherimos, pues no resuelve el problema del método a usar, dejando, a su juicio, abierta la puerta para que recrear o descrear el texto constitucional, justificando así en forma la concepción que a priori tenía el intérprete, pues parte de la base que el texto tiene un sentido propio por sí solo antes de ser interpretado, y en consecuencia, que el texto no habla por sí solo, lo que no es efectivo pues es el intérprete el que habla por el texto; si hablamos de acto de conocimiento se parte de la base que es el texto el que habla, ya que ello implicaría aceptar que el intérprete solo descifra algo que ya tiene existencia y sentido propio antes de ser interpretado, vale decir el texto es una verdad a priori, y su interpretación sería su desvelamiento, lo que lanza al suelo la noción ya enunciada de interpretación y hace volver a la vetusta escuela de la exégesis. A este respecto, nos resulta inevitable la referencia al pensamiento hermenéutico y los prejuicios (o más bien pre-juicios) del intérprete como realidad ineludible que condiciona el horizonte interpretativo, lo cual es negado por el pensamiento clásico. Es en virtud de este concepto que se puede recurrir a valores supremos como los derechos humanos (hay, por ejemplo, autores como Nogueira, que los ven como fuente suprema del Derecho constitucional ${ }^{49}$, y por ello los ubica por sobre el Derecho constitucional escrito), o la democracia como ideal supremo. Quienes fuimos alumnos de don Humberto Nogueira Alcalá sabemos, además, por sus enseñanzas, que la interpretación constitucional para la teoría democrática, deber sistemática, armónica y finalista, en lo que constituye uno de los pocos esfuerzos de la doctrina nacional por abordar el tema del método de interpretación.

Por el otro lado está la teoría de la interpretación como acto de voluntad, que el autor llama concepción realista. Acosta Sánchez ubica dentro de ella a autores como el francés Michelle Troper ${ }^{50}$, exponente

48 Id, ant.

49 En este sentido, ver Dogmática Constitucional, Humberto Nogueira AlCalá, ediciones Universidad de Talca, 1996.

50 Esta teoría parte de la base de la insuficiencia de los modelos tradicionales, y criticado al modelo de interpretación como acto de conocimiento, en este sentido en su obra ya citada, pág. 275: "solo una proposición científica puede ser verdadera o falsa (...) En consecuencia, pretender que una interpretación es exacta o inexacta implica aceptar que es un acto de conocimiento. Esta concepción no es aceptable. La crítica que se le ha hecho es una crítica ya antigua". 
de las nuevas corrientes del Derecho público francés, lamentablemente, poco conocido en nuestro medio. A este respecto, Acosta hace una cita textual de Troper, que reza de la siguiente forma: "el razonamiento interpretativo no presupone siempre que los principios de interpretación sean normas jurídicas", sosteniendo categóricamente que dichos criterios son políticos, con las consecuencias que de ello derivan. Acosta Sánchez señala que, para esta teoría, las normas carecen de existencia objetiva externa a la voluntad del intérprete, que no está sometido a regla alguna y que, por ende, todo acto de interpretación es necesariamente una creación de normas, vinculando esta teoría con las creaciones de la Corte Suprema norteamericana y los Tribunales constitucionales europeos, y con la comprensión por el intérprete de los grandes valores políticos plasmados en las constituciones europeas ${ }^{51}$.

Por otra parte, desde la visión del constitucionalismo norteamericano podríamos hablar de "interpretación originalista" y de "interpretación interpretativista", en lo que el Derecho europeo quizás llamaría interpretación restrictiva e interpretación extensiva. En el caso norteamericano nos remitimos a lo que ya se ha señalado antes en este trabajo $y$, en concordancia con lo anterior, cabe señalar que los originalistas, a nuestro juicio, buscan interpretar la Constitución solo a la luz de su historia fidedigna y su texto literal, siendo que los interpretativistas tienen en cuenta además otros factores: la historia, el contexto, la posición del intérprete, y aún más importante, el elemento teleológico, o conjunto de valores que están en cuestión a la hora de interpretar, valores que como ya se ha dicho son de naturaleza política, lo que ha llevado a hablar de judicial politics y judicial activism. Evidentemente, la corriente interpretativista es la que está más cerca del pensamiento hermenéutico moderno y, a nuestro juicio, más vinculada con la realidad, con el proceso político mismo y las exigencias actuales de real y total supremacía de la Constitución.

Otra forma de abordar el tema, puede ser distinguiendo entre interpretación formalista o materialista, según se centre, más bien, en uno u otro de dichos aspectos de la Constitución. Aquí, por ejemplo, podríamos comparar a la Supreme Court, que aborda los aspectos de fondo de la Constitución, muchas veces en claro desmedro de lo formal, con la Corte de constitucionalidad Italiana, cuya ley orgánica le impide cualquier "valoración de naturaleza política" sobre los actos del Parlamento. Valga aquí la crítica a la interpretación formalista que, por vía judicial en el caso chileno, ha empobrecido al Derecho

51. Ver en este sentido la ya citada obra de Troper, págs. 273 y sig. 
constitucional, a través de la mutilación por los tribunales de las reales herramientas de supremacía constitucional, tales como lo son, por ejemplo, la acción de protección y el recurso de inaplicabilidad de la ley por inconstitucionalidad, a los cuales los tribunales les han agregado -premeditadamente, sin duda- tal cantidad de requisitos formales previos al examen de fondo, que la gran mayoría de estas peticiones son declaradas inadmisibles, sin siquiera examinar si hay violación a la Constitución. Lo anterior merece una crítica muy fuerte, pues es un retroceso indesmentible en materia de justicia y supremacía constitucional. Lo anterior ha significado que los tribunales hayan optado por dejar sin efecto y sin aplicación las normas de la Carta Fundamental, dejando como letra muerta la supremacía constitucional y creando, de hecho, vacíos de control que no son propios del Estado de Derecho constitucional de derecho o Estado de derecho contemporáneo. Frente a este problema, en 1803 el juez Marshall falló que: "No es posible presumir que una cláusula constitucional haya querido dejarse sin efecto; esa interpretación resulta, por tanto, inadmisible salvo que las mismas palabras del texto la requieran..." y, en el mismo fallo, planteó y respondió la interrogante central de este tema, de la siguiente forma: "¿Que un caso que surja al amparo de la Constitución debería resolverse sin que ella misma sea examinada? Esto es demasiado extravagante para que pueda sostenerse." 52 . Al parecer, en el lenguaje propio del caso "Marbury $v / s$ Madison", cabría calificar de "extravagantes" a nuestros tribunales, o, más bien, calificar su interpretación como de "extravagantemente formalista".

Finalmente, dentro de la doctrina nacional (sin perjuicio de lo ya citado), cabe destacar algunos trabajos nuevos que abordan estos temas, aunque no todos de forma frontal, señalando algunas reglas o normas a tener en cuenta, tales como:

a) Principio pro bomine $e^{53}$, o la interpretación más favorable a los derechos fundamentales.

a) El ya viejo y conocido principio de juridicidad ${ }^{54}$

52 Fuente: Marbury v. Madison (1, Cranch, 137, 1803).

Selección y traducción de extractos de la sentencia para "Materiales de Derecho Constitucional " a cargo del profesor J.M. Vidal, página web de la Universidad de Valladolid.

53 José Ignacio Martínez Estay, "El juez y los efectos de la Constitución en el tiempo", en Estudios Constitucionales, Revista del Centro de Estudios Constitucionales de la U. de Talca $n^{\circ}$ 1, Santiago, 2003. El mismo principio es enunciado por $H$. Nogueira en su ya citada "Dogmática Constitucional".

54 José Ignacio Martínez Estay, ob. cit. 
a) El principio de la buena $\mathrm{fe}^{55}$

a) El principio de eficacia integradora

b) La ya citada interpretación armónica sistemática y finalista.

c) Otros principios, como por ejemplo la presunción de constitucionalidad, profusamente utilizada por el Tribunal constitucional.

\section{Corolario}

Como se ve, no existe uniformidad de criterios en la materia, y los límites son muy amplios y, a ratos, muy similares entre sí; por lo que, en realidad, el problema del método puede ser más bien un círculo dentro del cual cabe cualquier cosa: literalismo, originalismo, formalismo, judicial activism, Legal realism, judicial politics, acto de conocimiento, acto de voluntad, etc. Podrían caber, incluso, teorías antidemocráticas, como las que transmutaron la carta de Weimar en uno de los sustentos jurídicos del nacional socialismo, lo que nos hace volver a la necesidad de la legitimidad, más aún si se habla de tipos de interpretación; pero, a pesar de ello, en ninguno de estos enfoques se habla de sistemas ni procedimientos interpretativos, y cuando se habla de reglas y métodos estos no son de aceptación general.

\section{Bibliografía}

- José Acosta SÁnchez: Formación de la Constitución y jurisdicción constitucional, Ed. Tecnos, Madrid, 1998.

- Ismael Bustos ConCHA: "La Constitución, su interpretación y la justicia constitucional", en La Revista de Derecho, Universidad Central, Santiago, abril de 1991, número dedicado a las $2^{\text {as }}$ Jornadas de Derecho Procesal constitucional, págs. 59 y sigs.

: Curso de Ética y Filosofía del Derecho Facultad de Ciencias jurídicas y sociales U. Central, Santiago, 2003. : "La Hermenéutica constitucional", Revista de Derecho, Universidad de Valparaíso, 1986.

: "A new approach to constitutional justice: profesor Dworkin's, an interpretative analysis about an interpretative approach", XXIV Jornadas Chilenas de Derecho Público, Santiago 1993.

55 En este sentido, "Derecho Constitucional chileno", José Luis CEA EgaÑa, ediciones PUC, y también José Antonio RAmírez ArRAyas, "Interpretación constitucional y principio de buena fe", en Estudios Constitucionales, Revista del Centro de Estudios Constitucionales de la U. de Talca $\mathrm{n}^{\circ} 1$, Santiago, 2003. 
: "Introducción al análisis de la Justicia constitucional", en Anuario de Filosofía Jurídica y Social, Edeval, año 1989.

- Eduardo García de Enterría: La Constitución como norma y el Tribunal constitucional", Editorial Civitas, Madrid, 1981.

: "La posición jurídica del Tribunal constitucional en el sistema español: posibilidades y perspectivas", Revista Española de Derecho constitucional, $\mathrm{N}^{\circ} 1$ volumen 1, eneroabril de 1981.

- Domingo Hernández E. La Constitución, su Interpretación y la Justicia constitucional, en La Revista de Derecho, Universidad Central, Santiago, abril de 1991, número dedicado a las $2^{a}$ Jornadas de Derecho Procesal constitucional, págs. 65 y sigs.

- Manuel Jiménez de PARga: en el prólogo de Formación de la Constitución y jurisdicción constitucional, de José Acosta Sánchez, Ed Tecnos, 1998.

- Segundo Linares QuinTANA: Reglas para la Interpretación constitucional. Ed. Plus Ultra, Buenos Aires, 1987.

- José Ignacio Martínez Estay: "El juez y los efectos de la Constitución en el tiempo", en Estudios Constitucionales, Revista del Centro de Estudios constitucionales de la U. de Talca $n^{\circ}$ 1, Santiago, 2003.

- Edwin Messe III: en Interpreting the constitution, varios autores, edited by Jack N. Rakove, "interpreting the constitution, the debate over original intent", Northeastern University Press, Boston, 1990.

- Humberto Nogueira Alcalá: "Dogmática constitucional”, ediciones Universidad de Talca, 1996.

- José Antonio Ramírez Arrayas: "Interpretación constitucional y principio de buena fe", en Estudios constitucionales, Revista del Centro de Estudios constitucionales de la U. de Talca $n^{\circ}$, Santiago, 2003.

- Francisco Rubio Llorente: "La interpretación constitucional", en La Forma del Poder, estudios sobre la constitución", Centro de Estudios constitucionales, Madrid, 1997.

: "Seis tesis sobre la jurisdicción constitucional en Europa", en La Forma del Poder, estudios sobre la Constitución, Centro de Estudios constitucionales, Madrid, 1997.

- Luis Carlos Sachica: El Control de la constitucionalidad. Ed. Temis, Colombia, 1988.

- Jeffrey M. Shaman: "Interpreting the Constitution: the Supreme Court's proper and historic function" en Judicial Politics Reading from Judicature, American Judicature Society, 1992, págs. 37 y siguientes. 
- Michel Troper: Por una Teoría Jurídica del Estado, Instituto de derechos humanos Bartolomé de las Casas, Universidad Carlos III, Madrid, 2001.

- Mario Verdugo Marinkovic: "La Interpretación constitucional", Gaceta Jurídica $\mathrm{n}^{\circ} 185$, Editorial jurídica ConoSur Ltda.

- Jerzy Wroblewski: Constitución y Teoría General de la Interpretación Jurídica, Ed. Civitas, Madrid 1985.

- Francisco Zúñiga Urbina: "Tendencias contemporáneas en la interpretación constitucional", publicado en el libro Interpretación, Integración y Razonamiento jurídico", Ed. Jurídica de Chile, 1992. 